\title{
Dehydration, Rehydration, and Hyponatremia: Cause for Alarm?
}

\author{
Roland J. Lamarine \\ California State University, Chico
}

\begin{abstract}
Current health culture suggests that sedentary individuals should be consuming at least eight, eight ounce glasses of water each day. This injunction further stipulates that the water requirement cannot be adequately met by consumption of sweetened, caffeinated, or alcohol containing fluids. An additional concern is that thirst may not serve as an adequate early indicator of hydration needs. These propositions are reviewed in light of current research findings and suggestions are submitted for appropriate emendation of these rules.
\end{abstract}

(C) 2003 Californian Journal of Health Promotion. All rights reserved.

Keywords: dehydration, rehydration, hyponatremia, water

Several years ago, this observer started noticing a proliferation of bottles of water being carried into the classroom by his undergraduate students. It was all the more noteworthy because these were early morning classes. After 37 years as an avid weight lifter and runner, this writer has never found it necessary to carry water, even while living and exercising in a hot climate. Admittedly, the writer's exercise regime does not include marathons but typically four to five mile runs, which would seem to be more demanding than sitting through a 50 minute lecture?

Students report that it is necessary to consume at least eight, eight ounce glasses of water daily. Despite seemingly ideal health, over more than five decades, this writer wonders if he is flaunting morbidity and early mortality due to chronic dehydration by not heeding this advice?

An investigation into this question lead to some intriguing results. A quick check of Internet sources found some persuasive arguments in favor of the $8 \times 8$ ( 8 glasses of 8 ounces of water each day) rule. Heido Rinella (2002) suggested that "despite what you may have heard lately, you do need to drink this $(8 \times 8)$ much ...water." Nutritionists seem to be linedup (Rinella, 2002) to support the 8 X 8 rule, which ostensibly is founded upon the recommendation of " 1 milliliter of water for every calorie burned during the course of the day." It is common for most of people to burn at least 2000 calories/day, which would suggest that they should be consuming at least 2000 milliliters or a bit more than two quarts $(8,8$ ounce glasses) of water daily (Rinella, 2002).

As a lifelong exercise aficionado (including weekly 10 mile hikes), this writer has let his thirst guide his water consumption. Imagine the dismay at reading the words of a physician suggesting that once you become thirsty, you are already starting to get dehydrated (Rinella, 2002)

Internet research went on to suggest that people do not obtain ample fluids from solid foods (funny, since animals and plants are predominantly water); that caffeine and alcohol laden fluids may do more harm than good, by leading to serious dehydration; that juice, soda, or even Gatorade have reverse osmotic effects that negates whatever hydration was desired from them; and that even bottled water is suspect, since many times it lacks essential trace elements such as boron, selenium, and nickel (Rinella, 2002)

The Internet is a good place to start a search but no academic search is complete without a review 
of the professional, peer reviewed literature. Fortunately, Heinz Valtin, M.D., an emeritus professor of physiology at Dartmouth Medical School recently completed an extensive study of this topic (Valtin, 2002).

Dr. Valtin began with an inquiry about for whom the $8 \times 8$ rule might apply and concluded that most recommendations were directed toward sedentary individuals with the prescribed volume of water increasing with elevated temperature and activity level. The original source for the $8 \times 8$ rule may be lost in the recent past but one fairly certain reference can be traced to the 1945 Food and Nutrition Board of the National Research Council's suggestion that "An ordinary standard for diverse persons is 1 milliliter for each calorie of food" (Food and Nutrition Board, 1945). Unfortunately, the next sentence seems to have been omitted in most present day interpretations. "Most of this quantity is contained in prepared foods" (Food and Nutrition Board, 1945).

The injunction to avoid caffeinated beverages has been tested recently and researchers found that in persons who regularly consume caffeinated beverages (at least once a week), there were no significant differences in hydration levels when equal volumes of combinations of beverages were consumed (Grandjean, Reimers, Bannick, \& Haven, 2000). These researchers found caffeinated and noncaffeinated beverages were equally effective in maintaining hydration. This research suggests that the oft-quoted admonition to avoid caffeinated beverages may not be well founded.

To a lesser extent, alcohol consumption has been shown to have negligible diuretic effects "when consumed in dilute solution after a moderate level of hypohydration induced by exercise and heat" (Shirreffs \& Maughan, 1997, p. 8750). These researchers discovered that exercise participants rehydrated equally well whether they consumed water or beverages containing up to $2 \%$ alcohol. They also noted, however, that liquids containing $4 \%$ alcohol produced a delay in the rehydration process.
How valid is the notion that relying on thirst as a sufficient indicator for fluid intake may result in dehydration because thirst is not an adequate mechanism to help maintain hydration? Scientific evidence does not support this idea either. A rise of $2 \%$ in osmotic pressure (increased ratio of salts to fluids) can elicit thirst, while the consensus of scientific opinion would define dehydration as beginning when osmotic pressure reaches approximately 5\% which is equivalent to at least a $3 \%$ loss of body weight (Weinberg \& Minaker, 1995). It appears that most individuals can safely rely on thirst as a reasonable indicator of their fluid needs.

\section{Water Dangers}

Water intoxication (hyponatremia) in a majority of cases reflects an excess of water in the body, rather than a decrease in sodium levels. This condition has been associated with the rave drug Ecstasy (methylenedioxyamphetamine) which can cause intense thirst. This drug has lead to reported deaths from fatal hyponatremia but fortunately this occurrence remains relatively rare (Valtin, 2002).

Too much water consumed during extensive (over 3 hours) exercise sessions can be as dangerous as too little. In addition to a large number of Food and Nutrition Board contestants who have recently failed to complete the swim, bike, and run competitions due to dehydration and hyponatremia , the recent deaths of a runner in the Boston marathon and another runner in the Chicago marathon have called attention to the problem of over consumption of water (Hobson, 2002).

A popular running journal ("Take Our Beaker Test, 1999, p.26) has presented a urine color chart to guard against the dangers of even slightly darkened urine. Again, the scientific evidence supporting this position is more subjective and related to the opacity of the urine (Valtin, 2002, p. 23). Though well intentioned, these warnings may serve to increase the unnecessary and potentially dangerous overconsumption of liquids by runners.

In summary, there is emerging evidence that what has been presented with good intentions, 
namely the need to consume a minimum of two liters of water daily and perhaps considerably more if a person participates in athletic endeavors, is advice that may lead to unnecessary health risks for a significant number of individuals. The concomitant advice that food, caffeinated beverages, sweetened liquids, and to a lesser extent, low percentage alcoholcontaining beverages are so dehydrating that they have little or no value in rehydration appears to also be erroneous or at least not based on solid science.

\section{Advice for Health Educators}

Clearly common sense is necessary in determining an appropriate level of fluid intake.
Proper hydration levels would be related to general health, specific medical conditions, climate, activity level, body size, and the availability of appropriate liquids. Current evidence suggests that thirst can indeed serve as a reasonable indicator of fluid needs.

As always, health educators have a primary role in acting as resource persons in health education, which includes selecting effective educational resource materials for dissemination. In the case of the $8 \mathrm{X} 8$ rule, health educators may have to go a step further in determining the authenticity and scientific efficacy of this advice.

\title{
References
}

Food and Nutrition Board, National Academy of Sciences. (1945). Recommended dietary allowances (rev.). National Research Council, Reprint and Circular Series, No. 122, 3-18.

Grandjean, A. C., Reimers, K. J., Bannick, K. E., \& Haven, M. C. (2000). The effect of caffeinated, noncaffeinated, caloric and non-caloric beverages on hydration. Journal of the American College of Nutrition, 19, 591-600.

Hobson, K. (2002, October 7). Don’t drink the water. U.S. News \& World Report, 62.

Rinella, H. K. (2002). Eight, 8-ounce glasses: Drink deeply. Chet Day's Health \& Beyond. Retrieved February 11, 2003, from http://chetday.com/eightglassesofwater2.htm

Schirreffs, S. M., \& Maughan, R. J. (1997). Restoration of fluid balance after exercise-induced dehydration: Effects of alcohol consumption. Journal of Applied Physiology, 83, 1152-1158.

Take Our Beaker Test. (1999 June). Runner's World, 26.

Valtin, H. (2002). "Drink at least eight glasses of water a day," Really? Is there scientific evidence for "8X8"? American Journal of Physiology, 283, R909-R1004.

Weinberg, A., \& Minaker, K. (1995). Council of Scientific Affairs, American Medical Association: Dehydration evaluation and management in older adults. Journal of the American Medical Association, 274, 1552-1556.

\author{
$\underline{\text { Author Information }}$ \\ Roland J. Lamarine, H.S.D. \\ Department of Health and Community Services \\ California State University, Chico \\ Chico, CA 95929-0505 \\ E-Mail: rlamarine@csuchico.edu
}

\section{An Invitation}

Readers are highly encouraged to respond with scholarly manuscripts that address the issue of water consumption and the scientific rationale for the $8 \times 8$ Rule. Also, readers are encouraged to respond to related issues such as cultural behaviors of carrying around water bottles, water addiction/obsession, the "keep your urine running clear" prescription, and the physiologic effect of plastic chemicals from water bottles. 